\title{
Resistência política como dispositivo pedagógico: Memórias de estudantes de teatro da UFRGS
}

\begin{abstract}
Political resistance as didactic device: Memories of theater students of UFRGS
\end{abstract}

Juliana Wolkmer ${ }^{1}$

Vera Lúcia Bertoni dos Santos ${ }^{2}$ 


\section{Resumo}

O trabalho reflete sobre a formação em teatro na Universidade Federal do Rio Grande do Sul (UFRGS), a partir de relatos de estudantes do curso de Teatro entre os anos de 1960 e 1973. A partir da metodologia da História Oral (MEIHY; HOLANDA, 2007) são tecidas relações com o contexto histórico do período de formação de cada um dos entrevistados, que abrange um contexto político marcado pela resistência à censura e às perseguições, vigentes no período da ditadura civil-militar brasileira. A reflexão sobre esse aspecto, na perspectiva de teóricos como Foucault (2000) e Larossa (1994), leva a pensar na resistência política como um dispositivo pedagógico de transformação.

Palavras-chave: Memória; história; formação; teatro; resistência política

\section{Abstract}

The work reflects on the training in theater at the Federal University of Rio Grande do Sul (UFRGS), based on reports from students of the Theater course between the years of 1960 and 1973. Based on the methodology of Oral History (MEIHY; 2007), relations with the historical context of the period of formation of each of the interviewees are woven, covering a political context marked by resistance to censorship and persecution, in force during the period of the Brazilian civil-military dictatorship. The reflection on this aspect, from the perspective of theoreticians like Foucault (2000) and Larossa (1994), leads to think of political resistance as a pedagogical device of transformation.

Keywords: Memory; history; formation; theater; political resistance

E-ISSN: 2358.6958

\footnotetext{
1 Doutoranda no Programa de Pós-Graduação em Artes Cênicas (PPGAC) - Universidade Federal da Universidade Federal do Rio Grande do Sul (UFRGS). jwolkmer@yahoo.com.br

2 Professora Dra. Associada e pesquisadora vinculada ao Programa de Pós-Graduação em Artes Cênicas (PPGAC) - Universidade Federal da Universidade Federal do Rio Grande do Sul (UFRGS). bertonica@gmail.com
} 
Este texto apresenta resultados de uma pesquisa desenvolvida no (Programa de Pós-Graduação em Artes Cênicas da Universidade Federal do Rio Grande do Sul), entre os anos de 2016 e 2017, da qual se origina a dissertação de mestrado intitulada Formação em teatro na UFRGS (1960-1973): memórias de tempos de ousadia e paixão. Na pesquisa são produzidas, organizadas e analisadas informações sobre a história do ensino de teatro na Universidade Federal do Rio Grande do Sul (UFRGS) entre os anos de 1960 e 1973, a partir de entrevistas com egressos do Curso de Arte Dramática, Centro de Arte Dramática (ambos identificados pela sigla $C A D^{3}$ ) e Departamento de Arte Dramática (DAD) e de outros documentos.

As entrevistas deram origem a relatos memoriais que, relacionados ao contexto histórico e político de formação de cada um dos entrevistados, e organizados com base na metodologia da História Oral, possibilitam refletir sobre as bases da formação em teatro na UFRGS, lançadas num período historicamente turbulento, no qual a liberdade de expressão é ameaçada por ações coercitivas como a censura e as perseguições políticas.

De acordo com os teóricos Jose Carlos Sebe Meihy e Fabíola Holanda, referenciais nos estudos de História Oral no Brasil, a metodologia da História Oral define-se como "um conjunto de procedimentos que se inicia com a elaboração de um projeto e que continua com o estabelecimento de um grupo de pessoas a serem entrevistadas (Meihy \& Holanda, 2007, p. 15).

Nessa perspectiva, um projeto de trabalho relacionado à metodologia da História Oral prevê:

[...] planejamento da condução das gravações com definição de locais, tempo de duração e demais fatores ambientais; transcrição e estabelecimento de textos; conferência do produto escrito; autorização para o uso; arquivamento e, sempre que possível, a publicação dos resultados que devem, em primeiro lugar, voltar ao grupo que gerou as entrevistas. (Meihy \& Holanda, 2007, p. 15)

Considerados esses procedimentos metodológicos, elaborou-se o projeto de pesquisa cujo objetivo central era identificar práticas e teorias que influenciaram a formação em teatro da UFRGS e refletir sobre o ensino de teatro e suas relações com o tempo. A hipótese relacionada ao tema da pesquisa desenvolvida coloca o contexto histórico como um fator relevante nas transformações ocorridas no ensino de teatro no CAD/DAD no período delimitado.

Os dados da pesquisa foram produzidos a partir de entrevistas realizadas com um roteiro de questões do tipo semi estruturado, e complementados por documentos apresentados ou indicados pelos entrevistados (fotos, certificados, recortes de jornal, programas de eventos, dentre outros), ou consultados no Arquivo Histórico do Instituto de Artes (AHIA) da UFRGS (atas de reuniões de professores, grades curriculares, etc.) e em publicações diversas, impressas e digitais (livros, periódicos e informativos da internet).

\footnotetext{
3 Entre os anos de 1957 e 1965, a sigla CAD correspondia ao Curso de Arte Dramática; já entre os anos de 1967 e 1969, passa a corresponder ao Centro de Arte Dramática, que em 1970 é denominado Departamento de Arte Dramática, DAD, sigla atual.
} 
Foram entrevistados seis sujeitos (três homens e três mulheres), egressos do CAD/ DAD no período compreendido entre os anos de 1962 e 1973. São eles: a atriz e professora Alba Rosa dos Santos, nascida na cidade gaúcha de Passo Fundo (1941), e que frequentou o Curso de Arte Dramática desde 1961, formando-se em 1964; o artista bonequeiro Antônio Carlos Cardoso de Sena, nascido em Porto Alegre (1941), e aluno do CAD entre 1960 e 1962; a atriz, professora e historiadora Maria Luiza Filipozzi Martini, natural de Porto Alegre (1945), e aluna do CAD de 1966 até 1969, egressa do Curso de Formação de Atores; o professor e agente cultural Hamilton Dias Braga, nascido em Bagé/RS (1941), ingressante no DAD no ano de 1970, formado nos cursos de Direção Teatral e de Licenciatura em Arte Dramática, respectivamente em 1972 e 1973; a atriz e professora de teatro porto-alegrense Suzana Saldanha, formada nos cursos de Direção Teatral e de Licenciatura em Arte Dramática do DAD, concluídos em 1970 e 1972 , respectivamente; e o músico e ator Léo Vitor da Rosa Ferlauto, natural de Porto Alegre (1946), que frequentou o Curso de Formação de Atores do DAD entre 1970 e 1972.

Os encontros com os sujeitos das entrevistas ocorreram de forma presencial, mediante a intervenção direta da pesquisadora (Juliana Wolkmer), em locais escolhidos pelos entrevistados: a maior parte deles disponibilizou a sua residência para receber a entrevistadora (uma entrevistada apenas optou pelo encontro num café), o que conferiu um clima de cordialidade, descontração e, em alguns casos, intimidade, favorecendo a complementação das narrativas com documentos de acervos pessoais.

Para a elaboração deste texto foram selecionados alguns dados que apontam um dos aspectos explorados. Nesse sentido, ele parte de uma breve reflexão sobre as relações entre educação, teatro e política, no contexto político da formação universitária dos entrevistados, considerando dois períodos, correspondentes a dois momentos históricos relacionados à instauração e à vigência da ditadura civil-militar brasileira.

As partes subsequentes do texto enfocam os fragmentos dos relatos memoriais dos egressos entrevistados: as memórias referentes ao primeiro momento, correspondentes a experiências vivenciadas no período anterior ao golpe militar de 1964, caldeadas na Campanha da Legalidade ${ }^{4}$, e que contou com a participação de muitos artistas e estudantes de teatro; os depoimentos correspondentes a experiências dos anos finais da década de 1960, segundo momento evidenciado, que correspondem principalmente aos anos de 1969 e 1970, período emblemático para a história do CAD/DAD, quando o afastamento do diretor do curso na época, Gerd Bornhein, e de outros professores, levou os estudantes do curso a assumirem o controle das aulas, num gesto coletivo de resistência, de viés revolucionário.

De modo geral, os relatos memoriais concedidos pelos sujeitos das entrevistas são atravessados por questões políticas, que, inevitavelmente, influenciaram a pedagogia da época, seja de modo positivo ou negativo. Sob essa ótica, o texto propõe-se a compreender a resistência política dos protagonistas daquele momento histórico como um dispositivo pedagógico de transformação significativo à reflexão acerca do momento presente.

\footnotetext{
4 Mobilização civil e militar ocorrida no Sul e Sudeste do Brasil, em 1961, após a renúncia de Jânio Quadros da presidência do país, sob liderança de Leonel Brizola (então governador do Rio Grande do Sul) e do General José Machado Lopes. Na ocasião, diversos políticos e setores da sociedade defendiam a manutenção da ordem jurídica que previa a posse de João Goulart (Jango).
} 


\section{Teatro, política e educação em tempos de autoritarismo}

Em momentos históricos de forte engajamento e sectarismo, o discurso adquire papel decisivo. No período da ditadura civil-militar brasileira, a palavra, instituição de poder, passa a ser privilégio de poucos; e o teatro assumidamente político busca socializá-la. O dramaturgo e encenador alemão Bertolt Brecht (1967, p. 46) reflete sobre o papel libertador do teatro:

\footnotetext{
Nosso teatro precisa estimular a avidez da inteligência e instruir o povo no prazer de mudar a realidade. Nossas plateias precisam não apenas saber que Prometeu foi libertado, mas também precisam familiarizar-se com o prazer de libertá-lo. Nosso público precisa aprender a sentir no teatro toda a satisfação e a alegria experimentadas pelo inventor e pelo descobridor, todo o triunfo vivido pelo libertador.
}

O regime civil-militar instaura-se no Brasil no ano de 1964, justificado pela luta contra o comunismo e pela garantia da segurança nacional, abalando a soberania do país e a liberdade de expressão e de escolha dos seus cidadãos. O desejo da classe dominante de eternizar a si e ao seu poder orienta a criação de padrões, códigos e valores, ou seja, a apropriação da produção artística pela burguesia é voluntária e intencional. Com os principais órgãos representativos sob intervenção militar, a reação ao autoritarismo instituído evidencia-se forte no ano de 1968, momento em que os estudantes, ao lado de artistas e intelectuais, assumem a vanguarda da oposição.

O binômio "teatro e política" passa a sinalizar perigo, a gerar incômodo, desconfiança; e os ambientes formativos ou profissionalizantes relacionados ao teatro, assim como a cena teatral propriamente dita, passam a ter seus discursos vigiados, controlados, cerceados na sua liberdade de expressão.

As medidas de controle das ações de formação e difusão de arte e cultura por parte do Estado justificam-se, não raro, pela busca de uma desejada neutralidade dos espaços educativos, que costuma ser apoiado por diversos setores da sociedade civil, que se fazem representar nas mídias.

No sistema educacional, o pensamento positivista, corrente filosófica emergente na França no século XIX, exerce forte influência, na medida em leva a compreender o professor como figura detentora do saber, livre de ideologias e julgamentos de valor, supostamente isenta de preconceitos.

Essa ilusão de uma "educação neutra", que atinge o ensino nos seus mais diversos níveis, ignora os condicionamentos históricos e sociais das instituições e dos sujeitos que as integram, negando a própria natureza do processo educacional, cuja construção só é possível a partir da união de grupos, ou pessoas, em torno de um projeto político pedagógico que corresponda às necessidades e interesses da sociedade que esses grupos ou pessoas representam, ou desejam representar.

Tais reflexões levam a pensar sobre as escusas intenções de um projeto educacional dito "neutro"; e a questionar, no bojo de um projeto político pedagógico que se pretenda emancipatório, ou libertador, a adequação, e a possibilidade, de abordar conteúdos educacionais de forma "neutra", destituída de problematizações de cunho político, social e histórico crítico. 
Na concepção do educador Paulo Freire (1975, p.77), uma educação libertadora não pode ser fundamentada na concepção dos homens como seres vazios, a serem preenchidos por conteúdos, mas sim na "problematização dos homens em suas relações com o mundo".

Este texto parte da visão de alguns dos sujeitos de um período da história da UFRGS no qual a perspectiva de uma educação neutra por parte do Estado se impunha mediante ações de repressão e punição a qualquer ato que significasse ou sinalizasse questionamento do poder então instituído. A formação acadêmica desses sujeitos é, portanto, marcada por atos de resistência de estudantes e professores, cuja participação ocorre de diferentes formas.

\section{Envolvimento político, participação e silenciamento}

Os egressos Sena e Rosa foram os entrevistados cuja formação no CAD é mais remota, dentre os pesquisados. Suas formações datam de anos anteriores a 19645, quando a história do país era marcada por investidas dos militares para destituir do poder o presidente João Goulart, o que foi evitado pela chamada Campanha da Legalidade, na qual os dois entrevistados, assim como outros artistas de teatro da época, tiveram ativa participação.

Sena disponibilizou diversos documentos "do seu tempo de CAD", dentre eles, uma pasta na qual guardava fotografias e outros documentos do seu período estudantil, dentre eles, uma página estampada com o clássico distintivo da Legalidade. Ele rememorou a sua participação ativa no movimento em torno da Campanha da Legalidade, quando estudante do CAD:

Lembro da Campanha da Legalidade, por exemplo, não era de uma maneira muito organizada, mas os alunos participavam sim e se ligavam a esses movimentos. A gente se juntava aos alunos da filosofia e fazíamos atividades políticas. (Sena, 2016, p.6)

Outro documento dos guardados de Sena era uma matéria de jornal que noticiava a encenação do conflito entre Leonel Brizola e Carlos Lacerda, representados pelos bonecos do grupo de Teatro do qual participava. Ele lembra que, devido à quantidade de espectadores presentes ao evento, o trânsito de pedestres na rua chegou a ser obstruído, causando grande repercussão na cidade de Porto Alegre.

Considera-se as narrativas de Sena, bem como seu gesto, de guardar o distintivo da Legalidade e a referida reportagem junto às fotos do CAD, indícios dos vínculos entre esse momento histórico e a sua formação acadêmica como artista de teatro.

O depoimento de Rosa, por sua vez, evidenciou outro aspecto da participação dos estudantes do CAD nas questões de ordem política, caracterizado aqui como aleatório, ou casual, o que, de certo modo, significou um achado inusitado da pesquisa em relação à entrevistada.

\footnotetext{
5 Período em que vigora a Guerra Fria, conflito de ordem política militar, tecnológica econômica e ideológica, estabelecido de forma indireta entre os Estados Unidos e a União Soviética, que se estende às suas zonas de influência. Compreende o período entre o final da Segunda Guerra Mundial (1945) e o fim da URSS (1991).
} 
Isto ocorreu devido a um contato prévio da pesquisadora com uma imagem emblemática de Rosa, que estampa a capa de uma das quatro edições do Teatro em Revista, publicação do Teatro de Arena lançada no ano de 1968. A foto da personagem brechtiana Senhora Carrar, empunhando um fuzil, remetia à luta e a coragem das mulheres do povo; levando a uma idealização da figura da atriz e, consequentemente, a uma estimativa do potencial dos depoimentos a serem produzidos a partir da entrevista com ela: de narrar histórias de uma mulher aguerrida, engajada politicamente, que viveu e lutou ativamente contra a ditadura civil-militar.

No entanto, os relatos de Rosa contrariaram essa expectativa, evidenciando aspectos inusitados da sua passagem pelo CAD, que apontam para uma espécie de "anti-heroína", que, ao invés de enaltecer o seu comprovado passado de ativismo artístico e político, revela não ter, na época, muita consciência do significado das lutas anteriores e posteriores à ditadura civil-militar, nas quais se envolveu diretamente, e tampouco dos acontecimentos do Brasil de então.

Eu vivi épocas históricas! Na campanha do Brizola, da Legalidade, eu estava na pensão onde eu morava aqui em Porto Alegre e tinha um bancário lá. E eu estava lá muito tranquila e ele chegou e disse: 'O que está acontecendo? Você está aqui!? Mas que barbaridade!' Daí ele me levou lá para o Teatro de Equipe para ajudar. Mas eu pensei: 'Fazer o quê meu deus do céu? Eu não sei fazer nada!' [...]. Daí eu cheguei lá e me botaram na frente de uma máquina [de escrever] para fazer a inscrição de pessoas que estavam se prontificando a fazer, o quê eu não sei, aqui no Rio Grande do Sul. Inscrição para ajudar [na Campanha da Legalidade]. Meu Deus, eu fiquei o dia inteiro lá, estava louca de fome. Depois tinha que fazer cartazes e eu disse: 'Eu posso fazer, mas eu não sei o que tem que fazer!' Como é que as pessoas tinham consciência? Se eu que estava batendo [a máquina] e fazendo a inscrição não tinha, mas eles deviam ser mais sabidos do que eu. (Rosa, 2016, p. 4)

A atitude do vizinho de pensão de Rosa, convidando-a a colaborar com a causa política com a qual estava comprometido, parece denotar um entendimento senso comum na época: a vinculação dos artistas de teatro a questões políticas. No caso de Rosa, tudo indica que o seu envolvimento político se iniciou quase aleatoriamente, sem que ela percebesse a dimensão dos seus atos. Mal sabia a jovem estudante de teatro da sua participação num movimento decisivo da história brasileira; e que esse convite casual marcaria a sua trajetória no teatro.

Rosa relata que a companhia de alguns colegas foi determinante para que ela se envolvesse mais ativamente em questões políticas, mas que jamais se vinculou a qualquer partido político.

Em função de conviver com outras pessoas, eu passei a fazer parte daquela gente que ia para o bar tomar chope, comer sanduíche aberto e fazer a revolução, por isso que não deu certo! [...]. Inclusive, coisas que aconteceram no teatro, eu não tinha muita noção do que a gente estava fazendo exatamente, o que representava. Depois é que eu fiquei sabendo [...]. A gente saia de noite para fazer pichação, era uma loucura! Entregar folheto! Eu fazia porque os outros estavam fazendo, mas de mim era uma grande ignorância [...] no grupo é aquela história, você está no grupo, você aceita para ser aceita no grupo. (Rosa, 2016, p. 4) 
Sena mencionou também ter participado ativamente do chamado "Comitê de Resistência Democrática dos Artistas e Intelectuais" e comentou sobre o envolvimento dos estudantes atrelados ao Centro Acadêmico da Filosofia, caracterizados por ele como "os mais engajados politicamente". E Rosa lembrou que costumava agregar voluntários na sede do Teatro de Equipe. Localizado no centro da capital gaúcha, o Teatro de Equipe marcou a cena cultural de Porto Alegre entre 1958 e 1962, pela proposta de trabalho voltada à realidade brasileira; e constituiu importante ponto de apoio da Campanha da Legalidade. Criado e dirigido pelo jornalista Glênio Peres, o Equipe teve, entre seus importantes integrantes, Milton Mattos, Paulo José, Paulo César Pereio, Mario de Almeida, Ítala Nandi, Lilian Lemmertz e Nilda Maria.

A resistência, compreendida como dispositivo pedagógico, norteia e constitui os modos pelos quais os sujeitos pensam, agem e produzem; o que evidencia o quão valioso foi a participação política de Rosa e Sena na Campanha da Legalidade em termos de formação.

Outro aspecto a destacar nos depoimentos foram as menções ao envolvimento político dos professores do CAD. Rosa recorda que, no decorrer da sua formação no curso, pouco presenciou seus professores abordando questões políticas em sala de aula. A esse respeito, ela lembrou apenas, e muito vagamente, de comentários sobre política feitos pelo professor Fausto Fuser (ministrante da disciplina de Interpretação), que teria ido para a Polônia logo depois da ditadura ter sido instaurada no Brasil.

Sena também cita Fuser no seu depoimento, caracterizando-o como o único professor notadamente envolvido com questões políticas: um "homem de esquerda", mas que assumia suas posições na vida privada, e não na sala de aula.

Os relatos memoriais dos sujeitos da pesquisa apontam, de forma recorrente, para o fato de que os professores do CAD não falavam, ou pouco falavam, de política em sala de aula, o que, numa primeira análise, levaria a supor que eles estivessem alienados da realidade do país, ou conformados com ela.

A história mostra que a ideia de separar o teatro da política é uma falácia, pois ela nega a própria constituição do fenômeno teatral. Mas, em tempos de obscurantismo, controle e repressão da palavra, essa separação pode significar proteção, preservação, podendo constituir uma atitude política. No caso dos docentes do CAD mencionados nos depoimentos, essa hipótese parece confirmar-se, visto que, outros fatos relatados pelos ex-estudantes indicam que, naquele contexto, os professores optaram por se calar diante de eminentes pressões e ameaças sofridas, como medida de sobrevivência da própria instituição pela qual se entendiam responsáveis.

De modo geral, os relatos que levam a crer que o "silêncio político" que pairava nas salas de aula do CAD entre 1960 e 1973, período de formação dos sujeitos da pesquisa, e o "pouco estímulo" ao debate político nas conversas de sala de aula não impediu que os docentes e discentes de então exercessem diversas atividades de resistência política, que marcariam não apenas as suas trajetórias pessoais e profissionais, mas a história de Porto Alegre e do Brasil. 


\section{Uma poética política da arte teatral}

A visão de um Curso de Teatro que resiste, em meio à repressão do regime militar, principalmente após a promulgação do Ato Institucional número $5^{6}$, em 1968 , tem por base os relatos dos entrevistados Martini, Braga, Ferlauto e Saldanha, que estudavam no CAD/DAD daquele período.

O ano de 1969 é marcado na história do curso por pelo menos dois episódios importantes: a montagem da Ópera dos Três Vinténs (1928), espetáculo com a estética revolucionária de Brecht, de grandes proporções para os padrões da escola até aquele momento, dirigido pelo professor carioca Luiz Paulo Vasconcellos, vindo do Rio de Janeiro para se integrar ao corpo docente do curso.

O outro episódio, prenunciado pelas pressões políticas sofridas pela comunidade do CAD, foi a cassação do então diretor do curso, Gerd Bornheim, expurgado pela ditadura civil-militar ${ }^{7}$ juntamente com outros colegas, professores do Curso de Teatro.

Martini conta que a temporada do exitoso espetáculo se encera quando o diretor do curso, Gerd Bornheim, é aposentado de forma compulsória; e menciona também a existência de uma "comissão expulsória, ${ }^{8 "}$ da qual participavam professores do Curso de Filosofia, que delatavam os colegas "de esquerda".

No começo foi uma batalha, nós [estudantes do CAD] e os alunos da filosofia fizemos o diabo! Tudo o que a gente podia fazer, a gente fez! Mas não houve jeito [...] aquele pessoal reacionário do curso de filosofia queria arrancar o "gás" do corpo docente de qualquer maneira [...] eles morriam de raiva do Gerd. (Martini, 2017, p.8)

A entrevistada rememora, com extremo pesar, a situação delicada do CAD no ano de 1969, quando, após concluir o Curso de Formação de Atores, ela inicia o curso superior de Direção Teatral e enfrenta, junto a seus colegas, o expurgo de Bornheim e de outros importantes professores:

Eu não completei o curso, eu saí de raiva, porque o Gerd foi expulso e o Gerd foi uma figura [muito emocionada, a entrevistada chora], que além de impulsionar todas as nossas iniciativas, sempre estava atento. (Martini, 2017, p.7)

Outros professores lembrados por Martini foram: Dionísio Toledo (da disciplina de Literatura dramática), segundo ela, um "homem de esquerda", que também enfrentou problemas políticos, sendo cassado; e as demais professoras de Literatura dramática da época, Réassylvia Kraeff de Souza, Maria Luiza de Carvalho Armando e

\footnotetext{
6 Emitido pelo governo militar do então presidente Artur da Costa e Silva, o Al-5 foi o mais duro golpe na democracia; e deu poderes quase absolutos ao regime militar. Dentre outras medidas: concedia poder ao Presidente da República para suspender os direitos políticos de qualquer cidadão brasileiro pelo período de 10 anos; proibia manifestações populares de caráter político; concedia poder ao Presidente da República para cassar mandatos de deputados federais, estaduais e vereadores; suspendia o direito de habeas corpus (em casos de crime político, crimes contra ordem econômica, segurança nacional e economia popular); impunha a censura prévia para jornais, revistas, livros, peças de teatro e músicas.

7 O decreto-lei $n^{\circ}$ 477, de 26 de fevereiro de 1969, também chamado de "Al-5 das universidades", foi assinado pelo então presidente Artur da Costa e Silva, com o intuito de punir com expulsão professores, alunos e funcionários de universidades acusados de subversão ao regime militar. Os professores cassados eram impedidos de trabalhar em instituições de ensino pelo período de cinco anos, os estudantes ficavam proibidos de cursar qualquer universidade pelo período de três anos.

8 Comissão Parlamentar de Inquérito (CPI) é uma investigação conduzida pelo Poder Legislativo, que transforma a própria casa parlamentar em comissão para ouvir depoimentos e tomar informações diretamente. Para realizar os seus trabalhos a CPI tem os mesmos poderes de investigação de uma autoridade judicial.
} 
Maria da Glória Bordini, que haviam sido contratadas como professoras auxiliares de ensino do CAD, mas foram logo demitidas, apesar do abaixo-assinado realizado pelos estudantes do Curso para que permanecessem.

Os depoimentos de Sena e Martini referem-se também ao professor Ângelo Ricci (da disciplina da História da Literatura Teatral), outro protagonista daquele período, mas os relatos em relação ao seu posicionamento político geram divergências: Sena refere-se a Ricci como um "reacionário horrível"; entretanto, a visão de Martini suscita dúvidas, pois, embora num primeiro momento da entrevista ela o tenha descrito de forma taxativa, como uma pessoa "de direita", noutro, no qual relembrou a participação dos estudantes na ocupação do prédio da Filosofia, ela pareceu relativizar seu entendimento:

O Ricci era uma pessoa, que embora ele fosse absolutamente "composto" e não tivesse nada a ver com a esquerda, na verdade quando a gente tomou o prédio da filosofia, e éramos todos, ele impediu que a polícia entrasse no prédio [...]. (Martini, 2017, p. 8)

Martini rememora, com muita emoção, a "tomada do CAD" em protesto, feita pelos estudantes no sentido de assumir a responsabilidade sobre o funcionamento do Departamento, mantendo o espaço do Curso e evitando o seu fechamento:

Nós tomamos esse prédio para protestar contra os expurgos dos professores, contra a ascensão da direita e contra a comissão de professores de dentro do próprio curso. Se bem que, eles não tinham alternativa dentro do curso. Claro que eles pegaram os mais reacionários para fazer isso, para expulsar os próprios colegas. Eles não queriam fazer isso, mas tiveram que fazer, foi um horror! (Martini, 2017, p.8)

Segundo os depoimentos, a falta de um corpo docente que garantisse a continuidade das aulas do CAD levou os estudantes do último ano do Curso a ministrarem aulas para os alunos ingressantes no curso. Conforme Braga (2016), as aulas da disciplina de Expressão Corporal, por exemplo, foram assumidas pelas estudantes veteranas Graça Nunes e Irene Britzke (que anos mais tarde integrariam o quadro docente da UFRGS).

A alternativa encontrada para garantir a sobrevivência do Departamento no ano de 1970 foi compartilhar a responsabilidade pelas aulas com os estudantes veteranos e manter o prédio em atividade, contando com a colaboração da comunidade como um todo. Martini recorda de ter organizado a encenação de um fragmento do texto Woyzeck (1879), do alemão Georg Büchner, da qual participaram os estudantes calouros.

Ficou uma confusão, porque a gente não sabia como ia ficar a situação do Luiz Paulo [Vasconcellos] e da Lena [professora Maria Helena Lopes]. Eu lembro que a gente fazia espetáculos para não fechar o CAD, para ter o espaço sempre ocupado [...] a gente ficava lá dentro para não fecharem o Curso de Arte Dramática, a gente fez tudo o que pode para manter vivo aquele espaço. Foi uma coisa impressionante aquilo, nós mantínhamos o CAD dia e noite funcionando com espetáculos! (Martini, 2017, p.9) 
Saldanha, também estudante do CAD no período dos expurgos, embora não tenha ministrado aulas no lugar dos professores, como alguns dos seus colegas, lembra do seu apoio ao movimento estudantil para manter o CAD em funcionamento: "Na época a gente pegava a vassoura, a gente varria, era uma escola viva"! (Saldanha, 2017, p. 5).

Sobre o posicionamento dos estudantes e professores do Curso de Teatro com relação à ditadura civil-militar, Braga relata que todos sabiam a respeito das repressões impostas pelo regime, o que exigia muita cautela, em função da grande perda que o curso havia sofrido em 1969 e da vigilância constante dos militares.

Entretanto, ressalta ele, o clima de controle que vigorava até mesmo dentro das salas de aula, não impediu o envolvimento dos estudantes do DAD com a União Nacional dos Estudantes (UNE), ${ }^{9}$ que, por lutar contra a ditadura civil-militar, atuava na clandestinidade desde 1965:

\begin{abstract}
A gente sabia [...] mas a minha formação específica no desenrolar do curso não teve interferência maior, porque a grande interferência tinha sido no ano anterior, com os professores sendo afastados [...] Não lembro da gente falar muito em aula, até porque em algumas disciplinas tinha a presença de uma pessoa que se tinha praticamente certeza que era um agente ou informante do DOPS. Interessante, fazia tempo que eu não me lembrava disso. Ele era aluno, o nome eu não me lembro, me lembro da cara, mas não me lembro do nome. (Braga, 2016, p. 5)
\end{abstract}

Saldanha destaca os encontros de estudantes, que aconteciam no Centro Acadêmico do Curso de Letras, e lembra o grupo de estudos sobre o livro O capital (1867) de Karl Marx, que se reunia no DAD. Ferlauto aponta que outro local que abrigava debates calorosos era o bar Alaska, localizado na chamada Esquina Maldita ${ }^{10}$, que se tornara ponto de encontro de artistas e intelectuais revolucionários da cidade.

Sobre o destino dos professores cassados, Saldanha recorda que Bornheim, num primeiro momento, viaja para a Alemanha, e depois para a França, onde vive até o período da anistia, quando retorna ao Brasil ${ }^{11}$. A entrevistada narra uma curiosidade sobre um período da estada de Bornheim em Paris, quando ele ministrava palestras em importantes universidades francesas e, para garantir seu sustento, trabalhava como porteiro do Hotel San Michel, no Quatier Latin.

A busca por compreender como o DAD funcionou com os poucos professores que restaram, e em que condições os estudantes tomaram a frente do Departamento, motivou uma consulta à documentação do AHIA, que resultou pouco frutífera, mas, por outro lado, reveladora. Da documentação referente ao ano de 1970, consta apenas um envelope, com a indicação: "Atas de 1970". Poucas folhas soltas constituem as chamadas "atas", que, conforme explicita a Ata de número 1, passam a ser apresentadas em formato resumido. Verifica-se que, curiosamente, as atas de reuniões de professores dos anos anteriores do CAD/DAD, registradas em grandes cadernos,

\footnotetext{
9 Organização política e estudantil brasileira, uma das principais representantes de alunos do ensino superior do país. Fundada em 1938, a instituição desempenhou um papel singular em momentos importantes do Brasil desde o início do século XX, sendo uma das portas de entrada para diversos políticos brasileiros, especialmente aqueles ligados a movimentos de esquerda.

10 Conjunto de três bares (Alaska, Copa 70 e Mariu's), situado no cruzamento da Avenida Osvaldo Aranha com a Rua Sarmento Leite, no Bairro Bonfim, nas proximidades da região central de Porto Alegre e diante do Campus Central da UFRGS.

11 Ao retornar para o Brasil, Bornheim volta exercer a docência no Curso de Filosofia da Universidade Federal do Rio de Janeiro (UFRJ) e posteriormente se aposenta, pela Universidade Estadual do Rio de Janeiro (UERJ).
} 
de forma extensa, detalhada e manuscrita, cedem espaço para folhas soltas, de conteúdo objetivo, que quase nada dizem dos atos que então se processavam, ou, nos seus poucos dizeres, muitos significam.

\section{Censura e resistência}

Em tempos de intervenção militar, o teatro, assim como todas as formas de expressão e comunicação, representava ameaça, e, como tal, devia enquadrar-se no modelo político de segurança nacional do governo. Nesse modelo, a censura era a forma mais visível de pressão exercida pelo Estado contra o teatro político, que o afrontava, desvendando a realidade do país através de encenações que mostram as contradições políticas e sociais existentes. Por outro lado, não era conveniente ao governo destruir por completo a classe artística, pois precisava sustentar uma máscara democrática frente à maioria da população; assim, aceitava, tolerava a existência dos grupos teatrais e liberava suas peças, mas as submetia a uma austera vigilância.

Destaca-se aqui o caráter político da Ópera dos Três Vinténs (1928), obra do dramaturgo e encenador alemão que revolucionou a cena teatral, colocando-a a serviço da transformação política e social. Segundo Brecht, numa sociedade dividida pela luta de classes, o efeito "imediato" da obra de arte requerida pela estética da classe dominante é o efeito de suprimir as diferenças sociais existentes na plateia, criando, assim, enquanto a peça vai sendo encenada, uma coletividade universalmente humana e não dividida em classes.

A função do drama "não-aristotélico", que Brecht preconiza, é dividir a plateia, removendo o conflito entre sentimento e razão tão incentivado pelo mundo capitalista. Brecht é uma referência para os artistas que desejam, através da arte, mostrar a realidade social no seu mecanismo de aprisionamento, interpelando a plateia não pela identificação passiva, mas através de um apelo à razão que requeira ação e decisão.

Saldanha, que era integrante do grupo de teatro Província, era a encarregada de levar os textos para a censura em um prédio do Departamento de Ordem Política e Social (DOPS), localizado na Avenida Paraná, bairro Navegantes em Porto Alegre. Ela lembra de uma ocasião específica em que visitou o lugar:

Eu sempre fui muito agitada [...] eu cheguei e disse que precisava logo do carimbo e o cara simplesmente me jogou numa cadeira e disse: 'Tá escutando esses gritos, aqui? Isso aqui é cadeia, é DOPS ${ }^{12}$ aqui em cima!' Eu cheguei na casa que nós [integrantes do Grupo Província] morávamos, na Barros Cassal, e as lágrimas corriam. Nós todos os dias sabíamos, nós vivíamos a ditadura. (Saldanha, 2017, p. 6)

Ferlauto comenta que o público que costumava assistir a peças do CAD/DAD era restrito e não variava muito: "era uma tribo", mas conta que a Ópera dos Três Vinténs (1928), foi uma exceção, pois teve grande repercussão na cidade. O entrevistado relata que textos com teor político eram encenados com frequência, mesmo que tivessem de passar pelo "crivo" da censura. Ele conta que apesar das encenações

12 Departamento de Ordem Política e Social (DOPS) instituído em 1928. Órgão do governo brasileiro, utilizado principalmente durante o Estado Novo (1937 1945) e mais tarde na Ditadura Civil-Militar de 1964, cujo objetivo era censurar e impedir movimentos políticos e sociais contrários ao regime no poder. 
terem caráter estudantil e funcionarem como exames acadêmicos, também precisavam ser avaliadas pelos censores, visto que as suas apresentações eram abertas a público.

Interessante é o fato de Ferlauto mencionar a montagem do texto $O$ assalto, do dramaturgo José Vicente de Paula (1967), também rememorada por Braga, que lembra de ter desempenhado o papel de um bancário na peça. A montagem é um exemplo oportuno do caráter político das peças encenadas no CAD/DAD:

[...] o que eu lembro, da história [da peça] é que esse bancário se desilude com o ser humano, que era uma coisa que aconteceu muito naquela época. A revolução transformou o Brasil e na época era diferente do que a gente está vivendo agora [2016]. Para mim isso que a gente está vivendo agora é um monstro ditador muito pior do que naquela época, porque antes a gente sabia quem era o inimigo. (Braga, 2016, p. 8)

Em relação às atitudes de resistência dos estudantes e artistas e suas reverberações, considerando as perseguições ocorridas no período da ditadura civil-militar, Rosa relata que nunca fora presa, apesar de ter sido levada com colegas ao Palácio da Polícia ${ }^{13}$ algumas vezes:

Eu vivi a época de querer modificar o mundo! A gente fazia tudo que era besteira e tinha sempre um monte de polícia cuidando da gente. Levavam a gente e eu não sabia o porquê que a gente ia. Eu fui convidada com outras pessoas para ir ao Palácio da Polícia, depois é que eu me dei conta que aquilo que a gente sofria era violência psicológica, uma tortura psicológica. Nós ficávamos sentados, eu e os meus colegas [...] a noite inteira, a gente não sabia o que estava fazendo, eu não sabia o que eu estava fazendo lá, depois que eu entendi. Mas tu vê, eu era uma idiota! Mas depois a gente saia de lá e achava uma maravilha contar para os outros essas histórias e tomar chope e fazer revolução e daí chamavam a gente de novo, era um saco! (Rosa, 2016, p.4)

Rosa lembra um episódio marcante do ano de 1968, ocorrido no Teatro de Arena, quando ela desempenhava o papel de Teresa Carrar na peça Os fuzis da Senhora Carrar (1937), de Brecht. A peça tem como pano de fundo a Guerra Civil Espanhola ${ }^{14}$, e fora censurada por seu forte conteúdo político. No dia da estreia da montagem, os atores foram advertidos pela polícia, acusados de "porte ilegal de armas"; mas os fuzis da peça não passavam de carcaças de armas cedidas pelo próprio Exército, relata Rosa (2016, p.5) sobre o desfecho do episódio: "Trocaram as nossas armas por pau e a gente ficou brigando com umas madeirinhas".

O Teatro de Arena de Porto Alegre (TAPA) destacou-se como um dos locais mais conectados com os movimentos de resistência à ditadura civil-militar, não somente com a maioria dos artistas de teatro locais, mas também com o resto do país, juntamente com o Teatro de Arena de São Paulo, coordenado por Augusto Boal.

\footnotetext{
13 Localizado na Av. João Pessoa, 2050 - bairro Farroupilha, Porto Alegre e construído na década de 1950. No segundo andar do prédio, funcionou, entre 1964 e 1982, o Departamento de Ordem Política e Social (DOPS). No local, estima-se que pelo menos dez pessoas foram assassinadas e cerca de mil opositores da ditadura foram presos e torturados.

14 Conflito bélico deflagrado após um fracassado golpe de estado de um setor do exército contra o governo da Segunda República Espanhola. A guerra civil teve início em 1936 e terminou 1939, com a vitória dos militares e a instauração de um regime fascista, liderado pelo general Francisco Franco.
} 
Um dos motivos para a fundação do Teatro de Arena em 1967 foi a compreensão de que a arte não deveria retratar apenas a si mesma, mas representar o que estava ao seu redor, principalmente nos âmbitos político e social. No Teatro de Arena havia poucas pessoas do CAD, mas a maior parte dos seus fundadores eram oriundos do curso:

Lá do curso só tinha a Edviga [Falej], a Araci [Esteves], o Jairo [de Andrade] e eu. Foi ele [Jairo] quem teve a ideia de fundar um grupo, que depois se transformou no Arena. Era maluco também, depois mostrou aqueles porões lá para a gente, disse que ia fazer um teatro lá. Ele tinha as ideias dele, mas a gente não tinha muita noção, eu muito menos. A Edviga tinha, a Araci tinha um pouco, e dai que foi mais político. (Rosa, 2016, p. 5)

$\mathrm{Na}$ trajetória de Rosa observa-se um processo de conscientização política, estabelecido através do fazer teatral e da participação nos acontecimentos no período, marcado não só pelo enfrentamento político dos jovens diante do governo militar, mas também pelo preconceito em relação à profissão e pela série de dificuldades que ela trazia, além da sua não-regulamentação.

A repressão política dava-se dentro e fora da universidade, tanto que Braga narra que, aos vinte anos de idade, fora preso duas vezes, sem qualquer acusação ou justificativa formal. Sobre esses episódios tristes que marcam a sua vida pessoal, Braga (2016, p. 5) relata:

Para mim os acontecimentos políticos já tinham marcado muito profundamente antes, porque eu tenho [emociona-se] complica um pouquinho falar porque eu fui preso com vinte anos e quando eu estava fazendo o curso teológico [embarga a voz]. A violência, de certa maneira, eu já tinha sofrido, eu fiquei quarenta dias em uma solitária. Que coisa! Eu fiquei vinte anos sem conseguir falar disso! Quarenta dias numa solitária em um ambiente horrível, pequeno, sufocante, tinha um pé direito alto, as paredes pintadas de preto, a porta e o teto pintado de preto, uma luz que ficava acesa direto, o tempo inteiro. Era um prédio que foi destruído, que ficava aqui perto, onde é o viaduto, que era o quartel do exército, um prédio do século dezoito. Eu não morava em Porto Alegre ainda, eu vim preso de Bagé para cá, me trouxeram para cá.

Braga lembra que passou a ser alvo da desconfiança dos militares depois de ter passado um período no Uruguai, onde conheceu Leonel Brizola, o grande líder político da Campanha da Legalidade. Durante a ditadura civil-militar, muitos brasileiros descontentes com a situação política deixaram o país e seguiram para o exterior. O exílio atingia, sobretudo, uma parte da classe média intelectualizada, opositores de esquerda que o regime militar pretendia afastar do país. Na primeira fase do exílio, logo que os militares tomaram o poder (1964), os lugares mais procurados, pela proximidade de fronteiras com o Brasil, foram o Uruguai e o Chile. O exílio uruguaio expressava o verdadeiro sentimento dos que haviam deixado o país: a expectativa de que a volta seria breve.

Saliente-se que, embora nem todos os depoimentos aqui trazidos correspondam especificamente a fatos ocorridos nas salas de aula da UFRGS, eles revelam-se importantes para traçar o perfil desses estudantes, o que permite inferir que, assim como o CAD/DAD formava artistas e professores de teatro, seus espaços e ações de formação profissional eram constituídos e transformados pelos sujeitos que compunham o seu corpo discente. 


\section{Considerações Finais}

A arte é uma das formas de compreensão de um tempo e da sua sociedade. É também um instrumento de poder e uma maneira pela qual a cultura se revela, não apenas de forma estética, mas também social. O conhecimento do passado da sociedade em relação à arte possibilita refletir sobre o presente a partir de acontecimentos da nossa própria história. E, historicamente, o teatro, como toda a forma de arte, não é lugar de conforto, mas de inquietude, de transgressão.

Em âmbito nacional, a classe teatral se organizou e lutou de muitas formas para denunciar ao país a omissão e o cerceamento do governo dos militares, que, além de não assegurar condições dignas de trabalho para os artistas, reprimia qualquer manifestação que significasse ameaça ao poder estabelecido.

Investigar as formas pelas quais o teatro desafiou a ditadura civil-militar e o posicionamento do Estado perante as manifestações artísticas teatrais pode nutrir de entendimento e coragem as atuais e futuras gerações, visto que as ideias, aspirações, necessidades e esperanças daquela situação histórica particular assemelham-se muito às atuais.

As reflexões possibilitadas a partir dos dados da pesquisa aqui apresentada permitem pensar nos anos de ditadura como um período fecundo para o teatro, pois marcaram o desenvolvimento da dramaturgia, da encenação e da afirmação de uma geração que, independentemente de ações coercitivas ou punitivas, assumiu o teatro como atividade socialmente responsável, lançando-se na investigação de temas urgentes do processo sócio-político nacional.

A ideia de resistência política como um dispositivo pedagógico é resultante de uma urgência histórica. O filósofo e historiador francês Michel Foucault na sua obra Microfísica do Poder (2000, p. 244), identifica diversos elementos que constituem um dispositivo, dentre eles: "discursos, instituições, organizações arquitetônicas, decisões regulamentares, leis, medidas administrativas, enunciados científicos, proposições filosóficas, morais, filantrópicas".

Para o professor de filosofia da educação, Jorge Larossa (1994, p.57), o dispositivo pedagógico é "qualquer lugar no qual se constitui ou se transforma a experiência de si. Qualquer lugar no qual se aprendem ou se modificam as relações que o sujeito estabelece consigo mesmo".

Como se pode observar nos relatos aqui apresentados, o conhecimento adquirido na universidade não se restringia à sala de aula e aos professores do curso, pois se processava nas relações humanas que se estabeleciam no seu espaço, na forma de como ele era ocupado, nas discussões que tinham lugar nos corredores, nas mesas de bar, no movimento estudantil, na vivência universitária como um todo, em conexão com o movimento teatral da cidade de Porto Alegre. Haja vista a relevância dos grupos de teatro citados nos depoimentos, tais como o Equipe, o Arena e o Província.

A resistência política durante a ditadura civil-militar no Brasil, com certeza transformou os modos de pensar e agir dos estudantes de teatro da época, que se sentiram impelidos, de certo modo, a repensar a prática teatral dentro e fora da universidade, protagonizando ações de resistência que a mantiveram viva, pulsante. 
Pensando nas reflexões aqui propostas, em relação ao momento presente pós 2016, de fragilidade da democracia do país, de recrudescimento de ideais conservadores e de cerceamento de manifestações artísticas, indaga-se: até que ponto a comunidade universitária do DAD, que hoje ocupa o lugar deixado pelos professores e estudantes vanguardistas daquele momento histórico, se identifica com o comprometimento institucional e com o espírito revolucionário das suas ações de resistência política?

A perspectiva deste texto é refletir sobre a história de luta dos professores e estudantes de teatro da UFRGS, parte importante da história do teatro de Porto Alegre, e, quem sabe, estabelecer diálogo com professores e estudantes de teatro de hoje, com vistas a questionar os dispositivos pedagógicos que operam atualmente e assumir um posicionamento responsável no sentido da transformação do teatro e da sociedade na qual se inserem.

\section{Referências}

BRAGA, Hamilton Dias. Entrevista concedida à pesquisadora Juliana Wolkmer. Porto Alegre, agosto de 2016.

BRECHT, Bertolt. Teatro Dialético. Rio de Janeiro: Civilização Brasileira, 1967.

FERLAUTO, Leo Vitor da Rosa. Entrevista concedida à pesquisadora Juliana Wolkmer. Porto Alegre, fevereiro de 2017.

FREIRE, Paulo. Pedagogia do Oprimido. Rio de Janeiro: Paz e Terra, 1975.

FOUCAULT, Michel. Microfísica do poder. Rio de Janeiro: Graal, 2000.

GUIMARAENS, Rafael. Teatro de Arena: palco de resistência. Porto Alegre: Libretos, 2007.

GUIMARAENS, Rafael. Trem de volta: Teatro de Equipe. Porto Alegre: Libretos, 2003.

LARROSA, Jorge. Tecnologias do eu e educação. In: SILVA, Tomaz Tadeu. O sujeito da educação. Petrópolis: Vozes, 1994.

MARTINI, Maria Luiza Filippozzi. Entrevista concedida à pesquisadora Juliana Wolkmer. Porto Alegre, janeiro de 2017.

MEIHY, J. C. S. B. \& HOLANDA, Fabíola. História oral. Como fazer, como pensar. São Paulo: Contexto, 2007.

ROSA, Alba dos Santos. Entrevista concedida à pesquisadora Juliana Wolkmer. Porto Alegre, setembro de 2016. 
SALDANHA, Suzana. Entrevista concedida à pesquisadora Juliana Wolkmer. Porto Alegre, janeiro de 2017.

SENA, Antônio Carlos Cardoso de. Entrevista concedida à pesquisadora Juliana Wolkmer. Porto Alegre, novembro de 2016.

Recebido em: 26/09/2018

Aprovado em: 09/01/2019 